Int. J. Curr. Res. Med. Sci. (2017). 3(7): 128-137

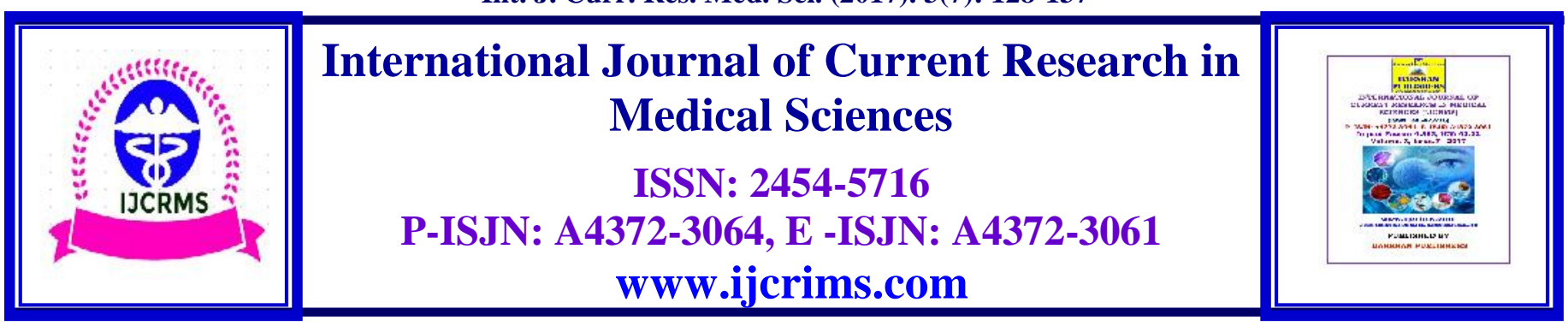

\title{
Acute and Long -Term Toxicity Study of Poora Parpam a Herbo - Mineral Siddha Drug
}

\author{
* Rajmohan M S, Swetha R, Sowmiya S \\ Department of Saatam sarntha maruthuvam nanju nool (Forensic Medicine and Toxicology) \\ Sivaraj Siddha Medical College, Salem, Tamilnadu, India \\ *Corresponding author:drrajmohanmd@gmail.com
}

\begin{abstract}
Safety is the fundamental principle in the provision of traditional medicine and herbal products. As siddha medicine is gaining pace everywhere, it is essential to prove the safety of all drugs. According to siddha literature poora parpam is efficient in the management of arthritis and its related complications. Since it is a mercurial drug it is mandatory to study its toxicity profile. Acute and long term toxicity studies were carried out in swiss albino mice and wistar albino rats following WHO guidelines mentioned for traditional herbal medicines. In acute toxicity study 10 times more than the therapeutic dose of drug prescribed was given as single oral dose to the test animals and no sign of mortality was observed. Long term toxicity studies were carried out in different groups in which test drug was administered orally to rats at dose levels of $0.1296 \mathrm{mg} /$ animal, $0.648 \mathrm{mg} /$ animal and $1.296 \mathrm{mg} /$ animal respectively. Detailed hematological, biochemical, morphological and histopathological evaluation of organs was performed for all animals at the end of the study. Haematogical and biochemical analysis revealed no abnormalities. Histopathological analysis of brain, heart, kidney, liver, lungs of treated groups does not show any signs of toxicity. Thus Poora parpam was well tolerated by the treated groups and showed the therapeutic dose mentioned in the literature was safe for human consumption.
\end{abstract}

Keywords: siddha medicine, poora parpam, WHO guidelines.

\section{Introduction}

Siddha system is the ancient traditional system followed in South India mainly in Tamilnadu. It incorporates many herbal, mineral and metal based medicines. Siddha medicines are becoming increasingly popular as an effective and relatively alternative to allopathic drugs. In order to make global acceptance the quality and its safety are under scrutiny though traditional practitioners prescribed them since long time.
In the recent past, several western research groups have highlighted these pitfalls reporting the prevalence and concentration of heavy metals in the traditional medicines. In siddha medicine the formulations are mainly prepared with metals and minerals so called as herbo-mineral preparations such as parpam, chenduram, chunnam, kattu, kalangu. It is mandatory to test siddha formulations, so that it will be safely prescribed for humans. All metal and mineral preparations in 
siddha are prepared under special chemical processes that 'detoxify' the toxic heavy metals and make them potential as a medicine. ${ }^{5}$ Strictly speaking; these constituents are thus not contaminants but ingredients deliberately included for a specific therapeutic purpose. India being a signatory to WTO, to promote its products in the international market, it is imperative to study their safety for human consumption. Pooram (calomel) is mentioned under minerals in the literature. Sitharamoola kuligai is one of the notable medicines with pooram in the treatment of arthritis, syphilis, cancer and leucorrhoea. ${ }^{1}$ Poora Parpam dealt in this study was taken from the literature veeramaa munivar vaagada thiratu a classical siddha literature written by Veeramaa munivar. Preclinical toxicity studies of herbo mineral drugs provide scientific justification for their traditional use and prove that they are safe and efficacious. So far no scientific evaluations were carried out in this drug for its toxicity profile. In this study acute \& long term toxicity studies were conducted in rodents to reveal its safety.

\section{Materials and Methods}

\section{Collection and authentication:}

The raw drug was Pooram (calomel) was purchased from the country drug merchant shop at Chennai. It was authenticated by Siddha Central Research Institute, Chennai.

\section{Detoxification / purification of pooram}

\section{Ingredients:}

$$
\begin{array}{ll}
\text { Pooram (raw) } & -35 \mathrm{gm}, \\
\text { Vettrilai (Piper bettle) leaves } & -8.75 \mathrm{gm}, \\
\text { Milagu (Piper nigram) } & -8.75 \mathrm{gm},
\end{array}
$$

\section{Methodology}

Vettrilai and Milagu were ground together and made into a poultice. Then one litre of water was taken in a mud pot and the poultice was mixed in that water. The raw drug Pooram was covered with a piece of clean dry cloth, so that it was not exposed outside. One end of the cloth was tied to a bamboo stick and placed horizontally over the opening of the mud pot. The raw drug Pooram in cloth was suspended in the above decoction. The vessel was constantly heated till decoction reduced by three fourth of its volume. Finally the Pooram was taken out of the cloth, washed with clean water and dried in sunlight. ${ }^{2}$

\section{Preparation of poora parpam:}

\section{Ingredients:}

Purified Pooram (Calomel) - 3/4 varaagan (13.65 gm),

Erukkam paal

(Latex juice of Calotropis gigantia) - 14 palam (490gm),

Vengayam (Juice of Allium cepa) - 14 palam (910ml)

\section{Methodology}

Purified pooram was placed in a clean dry cloth, covered and tied together. In a mud pot the above mentioned quantity of erukkam paal was taken and pooram covered within the cloth was placed inside the mud pot. The mud pot was constantly heated until latex juice remaining in the pot totally dried out. Pooram was removed from the cloth and washed with water. Then it was ground into paste with vengayam juice (Allium cepa) and made into a poultice. Small pills were made from the poultice and dried in shade. Pills were placed inside a mud plate and enclosed with similar size plate. Margins of the plate were covered with clay cloth and allowed to completely dry. Finally it was kept in a pit dug out of earth and puddam (incineration) was made with 40 palam (1400 gms) cow dung cakes approximately. Next morning, on being cooled mud plate was removed and finished poora parpam was segregated and ground into a fine powder. Parpam was collected and stored in a clean air tight container. ${ }^{3}$

\section{Particle size analysis using HR - SEM}

The HR- SEM was used to evaluate particle size its distributions, material homogeneity and inter metallic distributions. A representative portion of each sample was sprinkled onto a double side carbon tape and mounted on aluminum stubs in 
order to get a higher quality secondary electron image for SEM examination. The SEM is carried out by using FEI-Quanta FEG 200-High Resolution Instrument. Resolution used was 1.2 $\mathrm{nm}$ gold particle separations on a carbon substrate and magnification from a minimum of $12 \mathrm{X}$ to greater than 1, 00,000 X. Experimental procedure was done at SAIF, Indian Institute of Technology, Chennai

\section{Toxicity study of poora parpam}

The toxicity studies were carried out after getting permission from The Institutional Animal Ethical Committee clearance.

\section{(1248/ac/09/CPCSEA/04/IAEC 2011).}

\section{Test animals \& housing condition}

Test animals were obtained from The King Institute, Chennai and kept at animal house, National Institute of Siddha, Chennai. All the animals were kept under standard environmental condition $\left(22 \pm 3^{\circ} \mathrm{c}\right)$. The animals had free access to water and standard pellet diet (Sai Meera foods pvt.ltd, Bangalore).

The animals were allowed for acclimatization period of 7 days to laboratory conditions prior to the initiation of treatment. The females were nulliparous and non pregnant. Animals were identified by cage number, animal number and individual marking on fur with picric acid. The animals were housed in polypropylene cages provided with bedding of husk. Dark and light cycle each of 12 hours was maintained.

\section{Acute toxicity study}

Acute toxicity was carried out in Swiss albino mice of either sex with a single exposure of 10 times more than the recommended therapeutic dose of test drug and the study duration was 14 days. The study was carried out as per the WHO guidelines 1993. ${ }^{4}$ Swiss albino mice of 6 weeks age and weight approximately (20-25 gm). Both male and female 20 (10-male, 10 - female) were chosen. The test drug was insoluble in water, in order to obtain and ensure the uniformity in drug distribution; the drug was dissolved in $10 \%$ aqueous tween 80 solution with uniform mixing and it was administered to the test group animals in a single oral dose. The control groups were received equal volume of the vehicle alone. The animals were weighed before giving the drug. Since the clinical dose was $12 \mathrm{mg} / \mathrm{day}$ it was converted to animal dose $(0.216 \mathrm{mg} /$ animal $)$ and then administered to the test group animals. Observations were made and recorded systematically and continuously as per the WHO guideline after test drug administration. Animals were observed individually for the first $4 \mathrm{hrs}$, then periodically during the study period. Mortality and behavioral responses were observed during the study period. At the end of the study all the animals were sacrificed and necropsy was done. Individual weight of animals was determined before the test drug administration and daily for 14 days.

\section{Long term toxicity study}

Wister albino rats age of 6-8 weeks and weight around 150-200 gm of both male and female were randomly divided into four groups as per guidelines. Each group consists of 3 male and 3 female rats. The study was carried out for one month at different dose level $0.1296 \mathrm{mg} / \mathrm{animal}$, $0.648 \mathrm{mg} / \mathrm{animal}, 1.296 \mathrm{mg} / \mathrm{animal}$ because the clinical duration of human consumption of test drug is 8 days. The human therapeutic dose of Poora Parpam is $12 \mathrm{mg} / \mathrm{day}$. Poora Parpam was suspended in aqueous tween 80 solution (10\%). It was administered to groups I, II and III at dose levels of $(0.1296 \mathrm{mg} / \mathrm{animal}, 0.648 \mathrm{mg} / \mathrm{animal}$, $1.296 \mathrm{mg} /$ animal). The control animals were administered with vehicle only. Administration was given orally using an oral gavage once in daily for 30 days. All animal were observed twice daily for mortality during the entire study period. The clinical signs such as alertness, aggressiveness, passivity grooming, gripping, strength, touch responses, restlessness, tremors, convulsions, pain response, righting, reflex, pinna reflex, corneal reflex, papillary size, lacrimation, salivation, urination, writhing, skin color was noted once a day for the period of 30 days . Food and water intake was measured once in a day for 30 days. Weight of each rat was recorded on first 
day and at weekly intervals throughout the course of study and at the end of the study.

At the end of study the blood samples were collected by cardiac puncture using a syringe. The collected blood samples were studied for hematological parameters like haemoglobin, total red blood cell count, total leukocyte count, differential count and remaining blood was centrifuged at $3000 \mathrm{rpm}$ for 10 minutes and collected serum was used for laboratory investigations. Biochemical parameters like blood glucose, lipid profile, total bilirubin, direct bilirubin, indirect bilirubin, SGOT, SGPT, ALP, total protein, albumin, globulin, urea, creatinine, uric acid, calcium and potassium were determined. All the animals were sacrificed at end of the study under ether anesthesia. Gross necropsy of all animals was carried out and the morphological changes of organs like liver, kidneys, brain, heart, and lungs were noted and preserved in $10 \%$ formalin. The organ specimen (3 to 5 micron) were fixed in $10 \%$ formalin for 24 hours and washed in running water after 24 hours. Samples were dehydrated in tissue processor and then cleaned in benzene to remove absolute alcohol. Embedding was done by passing the cleared sample through three cups containing molten paraffin at $50^{\circ} \mathrm{c}$ and then a cubical block of paraffin made with $\mathrm{L}$ moulds, followed by microtome slicing and mounting on the slides. The slides were stained with haematoxylin and eosin stain.

\section{Statistical analysis:}

The clinical signs of intoxication, body weight changes, food, water consumption, hematological and biochemical parameters analyzed were subjected to computer software programme INSTA V3 version. The results were studied statistically by one way ANOVA followed by Dunnet ' $\mathrm{t}$ ' test. $\mathrm{P}$ value $<0.05$ was taken to indicate a statistical significant difference between the groups being compared.

\section{Results and Discussion}

\section{Acute oral toxicity study}

There was no mortality observed at the dose level of $0.216 \mathrm{mg} /$ animal (10 times more than the therapeutic dose). There was no significant differences in the body weight of all treated and control animals. Toxicity signs such as piloerection, salivation \& lacrimation were absent.

\section{Long term toxicity study}

No abnormal behavioral signs were observed during the study period of 30 days. The test drug Poora Parpam results no mortality in group I (0.1296 mg/animal), group II (0.648 mg/animal) and group III (1.296 mg/animal) dose levels. Treated groups exhibited normal body weight throughout the study period. No difference in food intake and water intake of control and treated group animals observed during the period of study. The hematological investigation conducted at the end of the study in treated group revealed no significant changes in the parameters, when compared with control group. Slight elevation in the lymphocyte count was observed in treated groups, but statistically not significant (Table.1). In treated groups there was no significant elevation in the levels of biochemical parameters, when compared with the control group. And the values obtained were within normal biological limits (Table.2, 2.1, 2.2). Gross pathological examinations of animals reveal no morphological abnormalities in control and treated groups. The histopathological study of the organs heart, lungs, kidney, brain and liver showed normal study in all control, group I, groups II, group III. (Figure: 2, 3, 4, 5, 6) 
Int. J. Curr. Res. Med. Sci. (2017). 3(7): 128-137

Table.1. Hematological parameters of long term toxicity study treated with Poora Parpam after 30 days

\begin{tabular}{cccccc}
\hline Category & $\begin{array}{c}\text { Haemoglobin } \\
(\mathrm{g} / \mathrm{dl})\end{array}$ & $\begin{array}{c}\text { Total }-\mathrm{WBC} \\
(\text { cells/cu.mm })\end{array}$ & $\begin{array}{c}\text { Neutrophil } \\
(\%)\end{array}$ & $\begin{array}{c}\text { Lymphocyte } \\
(\%)\end{array}$ & $\begin{array}{c}\text { Total }- \text { RBC } \\
(\text { cells/cu.mm })\end{array}$ \\
Control & $13.4 \pm 0.6$ & $4850 \pm 0495$ & $40 \pm 31$ & $55 \pm 24$ & $4.2 \pm 0.1$ \\
Group I & $15.5 \pm 2.2$ & $5833 \pm 2017$ & $21 \pm 09$ & $78 \pm 09$ & $5.8 \pm 1.2$ \\
Group II & $16.4 \pm 3.5$ & $4717 \pm 1598$ & $24 \pm 08$ & $76 \pm 08$ & $5.1 \pm 1.0$ \\
Group III & $14.0 \pm 2.5$ & $4750 \pm 1435$ & $24 \pm 08$ & $77 \pm 08$ & $5.5 \pm 1.3$ \\
\hline
\end{tabular}

ns - not significant, $\mathrm{n}=6$, values are expressed as mean \pm S.D (One way Anova followed by Dunnett's test)

Table.2. Biochemical Parameters of long term toxicity study treated with Poora Parpam after 30 days

\begin{tabular}{lllllll}
\hline $\begin{array}{l}\text { Biochemical } \\
\text { Parameters }\end{array}$ & $\begin{array}{l}\text { Glucose(R) } \\
(\mathrm{mg} / \mathrm{dl})\end{array}$ & $\begin{array}{l}\text { Cholosterol } \\
(\mathrm{mg} / \mathrm{dl})\end{array}$ & $\begin{array}{l}\text { HDL } \\
(\mathrm{mg} / \mathrm{dl})\end{array}$ & $\begin{array}{l}\text { LDL } \\
(\mathrm{mg} / \mathrm{dl})\end{array}$ & $\begin{array}{l}\text { VLDL } \\
(\mathrm{mg} / \mathrm{dl})\end{array}$ & $\begin{array}{l}\text { Triglyceride } \\
(\mathrm{mg} / \mathrm{dl})\end{array}$ \\
Control & $100 \pm 40$ & $68 \pm 07$ & $20 \pm 04$ & $22 \pm 07$ & $27 \pm 04$ & $133 \pm 20$ \\
Group I & $112 \pm 18$ & $70 \pm 10$ & $23 \pm 05$ & $22 \pm 08$ & $25 \pm 04$ & $127 \pm 17$ \\
Group II & $116 \pm 37$ & $67 \pm 05$ & $22 \pm 05$ & $20 \pm 06$ & $25 \pm 06$ & $124 \pm 28$ \\
Group III & $90 \pm 25^{\mathrm{ns}}$ & $71 \pm 04$ & $24 \pm 02^{\mathrm{ns}}$ & $22 \pm 06$ & $25 \pm 04$ & $129 \pm 18$ \\
\hline
\end{tabular}

ns - not significant, $n=6$, values are expressed as mean \pm S.D (One way Anova followed by Dunnett's test)

Table.2.1. Renal function test of long term toxicity study treated with Poora Parpam after 30 days

\begin{tabular}{cccccc}
\hline Parameters & $\begin{array}{c}\text { Urea } \\
(\mathrm{mg} / \mathrm{dl})\end{array}$ & $\begin{array}{c}\text { Creatinine } \\
(\mathrm{mg} / \mathrm{dl})\end{array}$ & $\begin{array}{c}\text { Uric acid } \\
(\mathrm{mg} / \mathrm{dl})\end{array}$ & $\begin{array}{c}\text { Calcium } \\
(\mathrm{mg} / \mathrm{dl})\end{array}$ & $\begin{array}{c}\text { Potassium } \\
(\mathrm{mg} / \mathrm{dl})\end{array}$ \\
Control & $28 \pm 16$ & $0.76 \pm 0.25$ & $2.51 \pm 0.20$ & $8.8 \pm 0.8$ & $2.7 \pm 0.4$ \\
Group I & $26 \pm 03$ & $0.69 \pm 0.10$ & $2.57 \pm 0.36$ & $8.9 \pm 0.8$ & $2.7 \pm 1.0$ \\
Group II & $28 \pm 07$ & $0.66 \pm 0.09$ & $2.38 \pm 0.50$ & $8.7 \pm 0.6$ & $2.6 \pm 0.5$ \\
Group III & $30 \pm 06^{\mathrm{ns}}$ & $0.72 \pm 0.12$ & $2.43 \pm 0.37$ & $9.1 \pm 0.6$ & $3.1 \pm 0.6$ \\
\hline
\end{tabular}

$\mathrm{ns}$ - not significant, $\mathrm{n}=6$, values are expressed as mean \pm S.D (One way Anova followed by Dunnett's test) 
Table.2.2. Liver Function Test of Wister rats in long term toxicity study treated with Poora Parpam after 30 days

\begin{tabular}{ccccccccccc} 
Parameters & $\begin{array}{c}\text { T.Bilirubin } \\
(\mathrm{mg} / \mathrm{dl})\end{array}$ & $\begin{array}{c}\text { D.bilirubin } \\
(\mathrm{mg} / \mathrm{dl})\end{array}$ & $\begin{array}{c}\text { I.bilirubin } \\
(\mathrm{mg} / \mathrm{dl})\end{array}$ & $\begin{array}{c}\text { SGOT } \\
(\mathrm{U} / \mathrm{dl})\end{array}$ & $\begin{array}{c}\text { SGPT } \\
(\mathrm{U} / \mathrm{dl})\end{array}$ & $\begin{array}{c}\text { ALP } \\
(\mathrm{U} / \mathrm{dl})\end{array}$ & $\begin{array}{c}\text { T. } \\
\text { protein } \\
(\mathrm{mg} / \mathrm{dl})\end{array}$ & $\begin{array}{c}\text { Albumin } \\
(\mathrm{mg} / \mathrm{dl})\end{array}$ & $\begin{array}{c}\text { Globulin } \\
(\mathrm{mg} / \mathrm{dl})\end{array}$ \\
Control & $0.9 \pm 0.1$ & $0.3 \pm 0.0$ & $0.6 \pm 0.1$ & $67 \pm 25$ & $77 \pm 31$ & $132 \pm 6$ & $7.0 \pm 0.9$ & $3.3 \pm 0.6$ & $3.7 \pm 0.3$ \\
Group I & $0.7 \pm 0.1$ & $0.3 \pm 0.1$ & $0.4 \pm 0.1$ & $70 \pm 23$ & $86 \pm 27$ & $142 \pm 25$ & $6.7 \pm 0.3$ & $3.4 \pm 0.4$ & $3.3 \pm 0.2$ \\
Group II & $0.7 \pm 0.2$ & $0.3 \pm 0.1$ & $0.4 \pm 0.2$ & $58 \pm 16$ & $66 \pm 23$ & $138 \pm 8$ & $6.8 \pm 0.5$ & $3.2 \pm 0.3$ & $3.6 \pm 0.5$ \\
Group III & $0.7 \pm 0.2$ & $0.3 \pm 0.1$ & $0.4 \pm 0.1$ & $57 \pm 16$ & $62 \pm 22$ & $134 \pm 20$ & $7.1 \pm 0.4$ & $3.3 \pm 0.2$ & $3.7 \pm 0.3$ \\
\hline
\end{tabular}

ns - not significant, $\mathrm{n}=6$, values are expressed as mean \pm S.D (One way Anova followed by Dunnett's test)

\section{HR SEM Analysis}

Poora Parpam reveals the particle size as $1-10 \mu$ (micron). The particles were homogenously distributed in the Parpam. And smooth surface of the particles enable its easy for absorption in the gastro intestinal tract. Hence the drug will have increased bioavailability. (Figure.1.)

Figure 1.

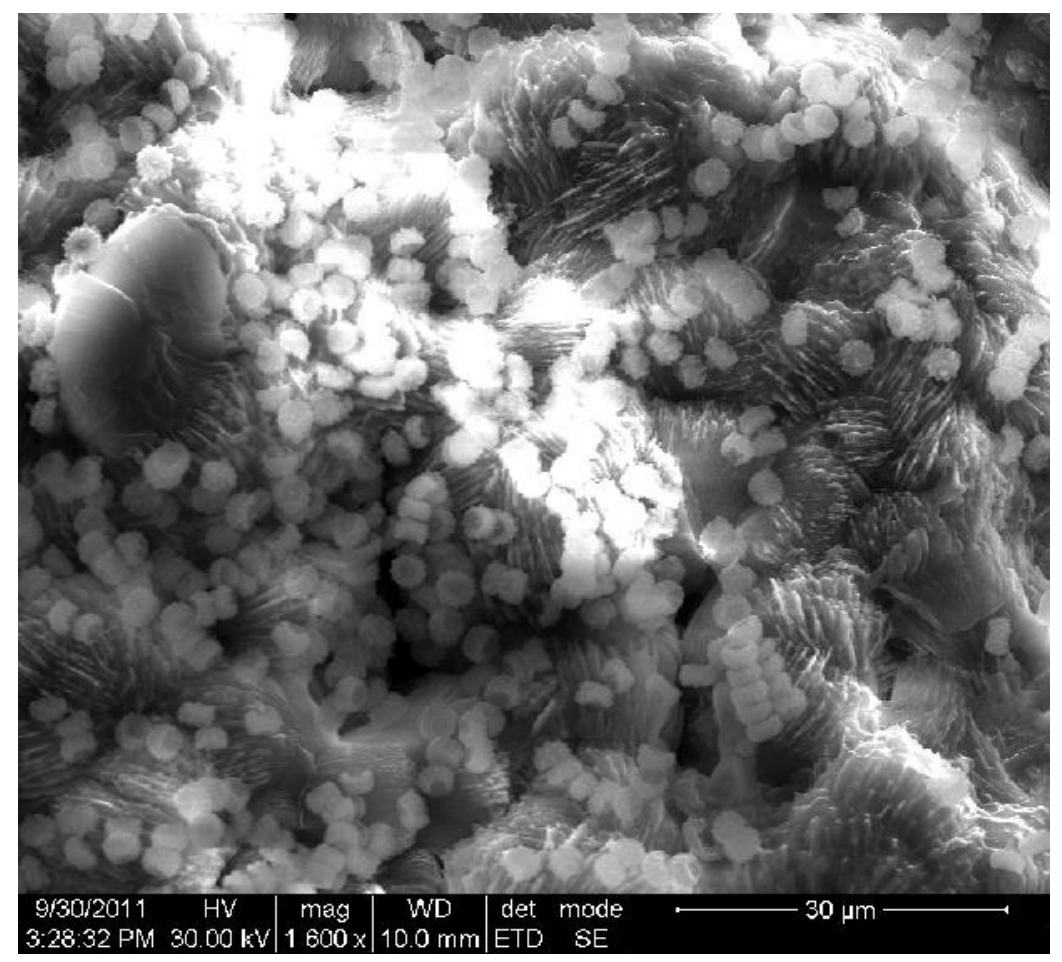


Int. J. Curr. Res. Med. Sci. (2017). 3(7): 128-137

Figure 2. Histopathological analysis of brain sections in control and treated groups

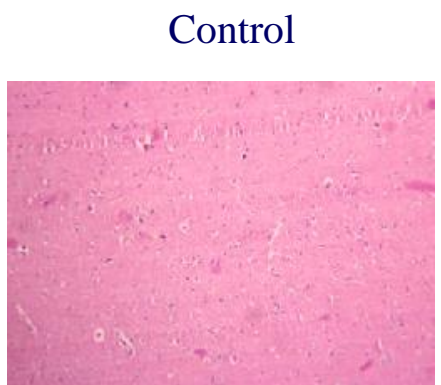

Group II

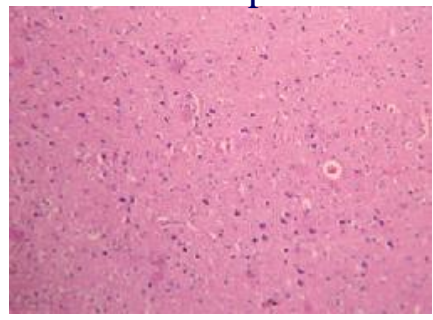

Group I

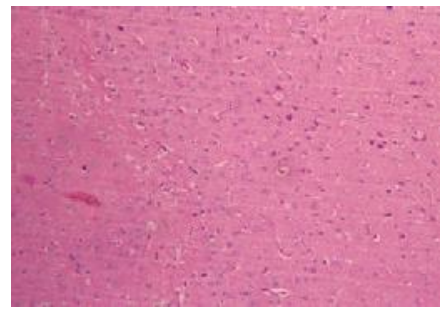

Group III

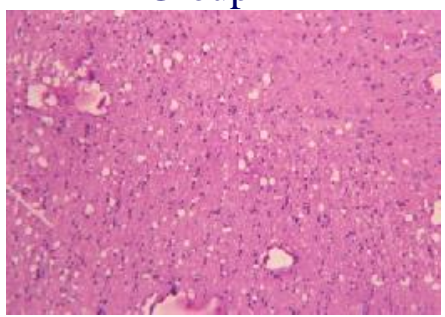

Figure 3. Histopathological analysis of heart sections in control and treated groups

Control

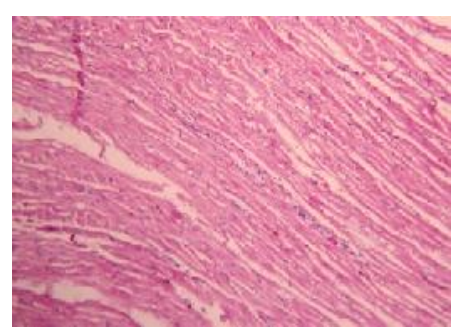

Group II

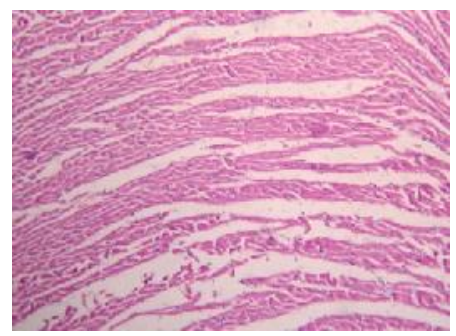

Group I

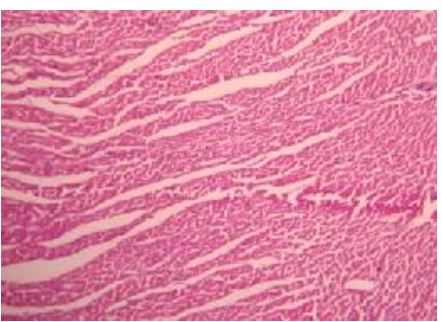

Group III

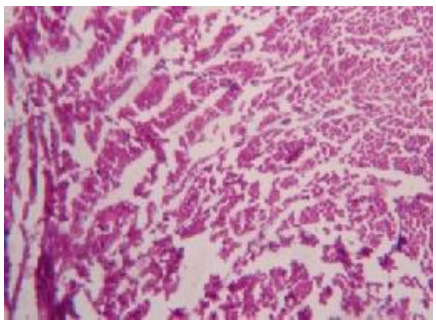


Int. J. Curr. Res. Med. Sci. (2017). 3(7): 128-137

Figure 4. Histopathological analysis of kidney sections in control and treated groups

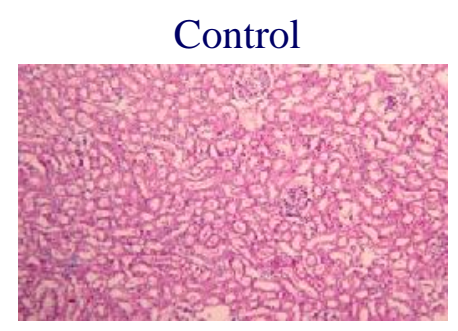

Group II

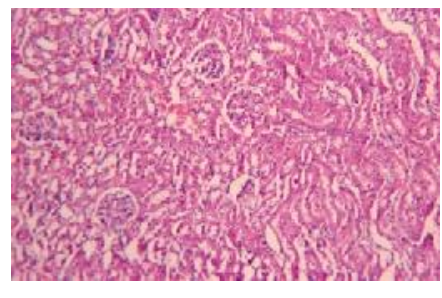

Group I

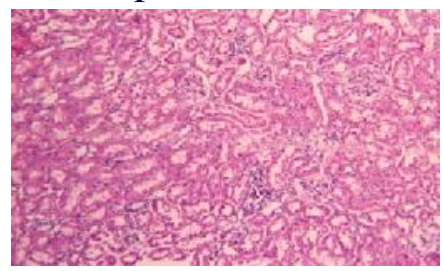

Group III

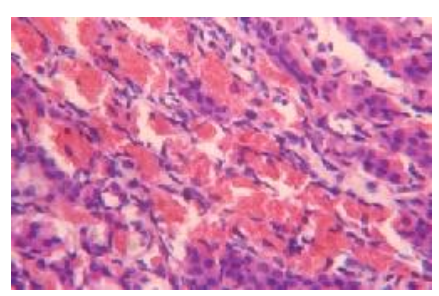

Figure 5. Histopathological analysis of liver sections in control and treated groups

Control

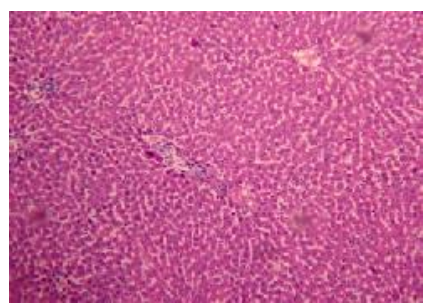

Group II

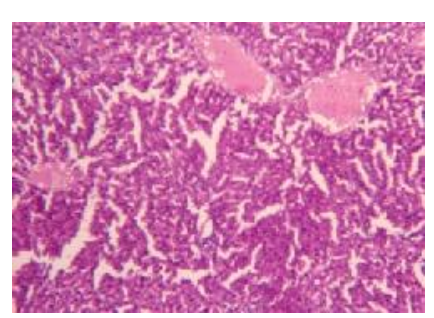

Group I

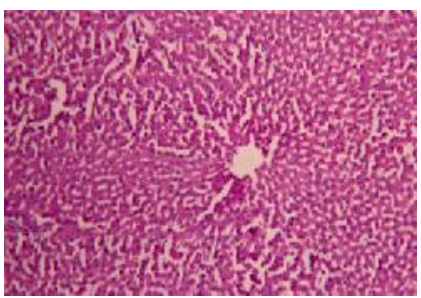

Group III

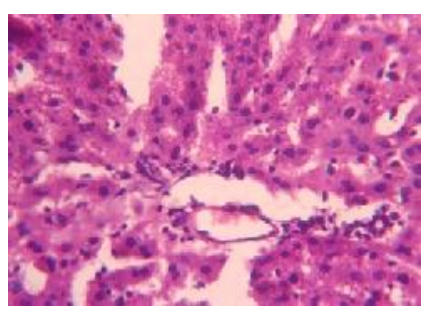


Figure 6. Histopathological analysis of lungs sections in control and treated groups

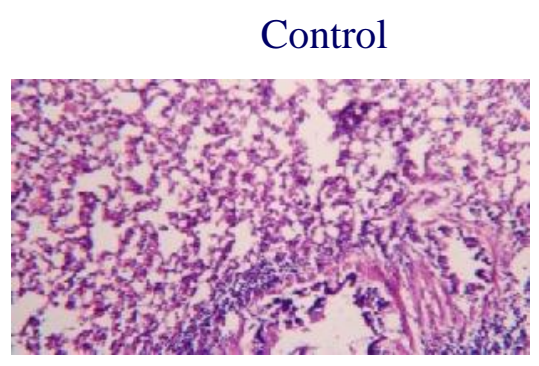

Group II

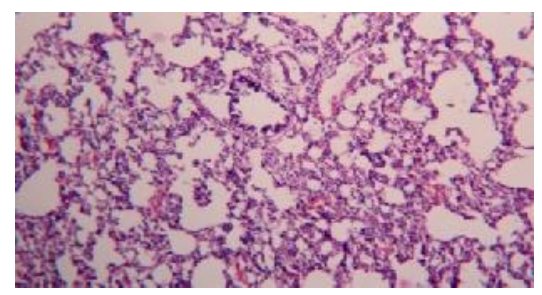

Group I

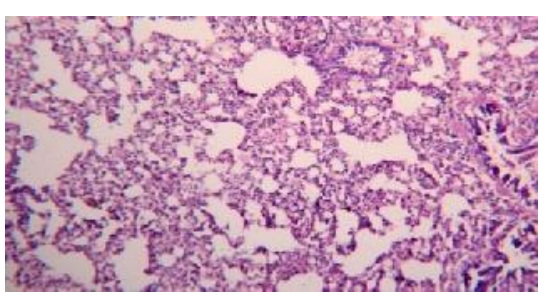

Group III

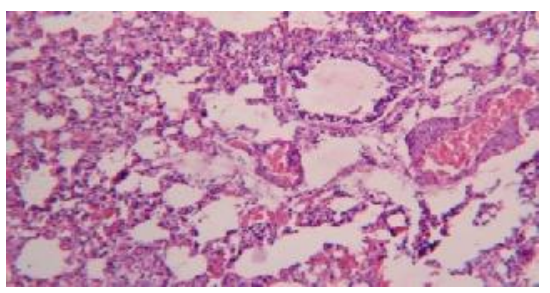

\section{Conclusion}

The above acute and long term toxicity study of Poora Parpam showed no sign of toxic effects and concluded that the therapeutic dose mentioned in the literature was found to be safer for human consumption. Hence further clinical trials are to be conducted for its global acceptance.

\section{References}

1. Dr.K.S.Murugesa mudhaliyar, H.P.I.M, Gunapadam Mooligai, $7^{\text {th }}$ edition 2003, published by Indian Medicine \& Homeopathy Dept. Chennai - 600106.
2. Dr.R.Thiagarajan L.I.M, Gunapadam Thathu Jeeva Vaguppu $4^{\text {th }}$ edition 2004, published by Indian Medicine \& Homeopathy Dept. Chennai -600106.

3. Anonymous, Veeramaa munivar vagadathiratu, Thamarai Noolagam, Chennai - 600026.

4. Research guidelines for evaluating the safety and efficacy of herbal medicines, Philippines, Manila: WHO, Regional Office, Western Pacific Region; 1993.

5. Dr.T.V.Sambasivam pillai, Dictionary of Medicine, Chemistry, Botany \& Allied Science (based on Indian Medical Sciences) Volume IV. 
Int. J. Curr. Res. Med. Sci. (2017). 3(7): 128-137

\begin{tabular}{|c|c|}
\hline \multicolumn{2}{|c|}{ Access this Article in Online } \\
\hline 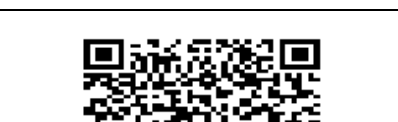 & $\begin{array}{l}\text { Website: } \\
\text { www.ijcrims.com }\end{array}$ \\
\hline 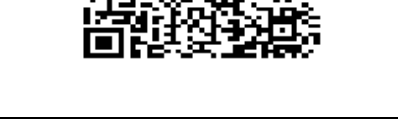 & $\begin{array}{l}\text { Subject: } \\
\text { Siddha Medicine }\end{array}$ \\
\hline Quick Response Code & \\
\hline
\end{tabular}

How to cite this article:

Rajmohan M S, Swetha R, Sowmiya S. (2017 Acute and Long -Term Toxicity Study of Poora Parpam a Herbo - Mineral Siddha Drug. Int. J. Curr. Res. Med. Sci. 3(7): 128-137.

DOI: http://dx.doi.org/10.22192/ijcrms.2017.03.07.019 